VARIA 


\title{
El vasco en la colonización de Brasil: la imagen de una ucronia
}

\author{
Jordi Cerdà \\ Universitat Autònoma de Barcelona \\ Elena Losada \\ Universitat de Barcelona
}

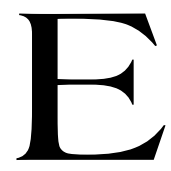

ntre los textos de la incipiente colonización de Brasil, uno de los hechos que más llama la atención son las referencias a la lengua vasca; y más cuando éstas provenienen, no de hombres de origen vasco, sino de portugueses. La enigmática lengua de la Península Ibérica fue sujeto de comparación entre las "muitas e diferentes línguas, desconhecidas, escuras, bárbaras, e que se não podem entender" como predicó años más tarde el padre Vieira. Puede incluso sorprendernos como, actualmente, en el Dicionário Aurélio da Língua Portuguesa, tiene como segunda acepción de la entrada "vasconço": "Linguagem ininteligível”. Brasil, un país con uno de los caudales lingüísticos más insólitos del planeta, recurre a un término foráneo y tan remoto como "vasconço" para referirse a una lengua extraña.

Sin embargo, la aparición de referencias a la lengua vasca entre los descubridores portugueses del Brasil entraba en unas coordenadas plausibles. No debemos olvidar que, en aquella altura, los marineros vascos disfrutaban de un reconocido prestigio, y el contacto entre éstos y portugueses debían ser frecuentes y prolijos. Tanto es así, que, en Oriente, el cronista Fernão Lopez de Castanheda, en 1531, consigna como algo natural el hecho que un joven sultán de la India, al haberse criado junto con marineros portugueses, castellanos y vizcaínos, hablase las tres lenguas y por ello se enorgulleciera: "E como se criara com os Castelhanos, sabia 
bem a sua língua, e a bizcaina e a Portugueza, e prezaba-se muyto de as falar". ${ }^{1}$

\section{1- Dos percepciones: lengua de bárbaros y lengua "pentacostal"}

Deberíamos, no obstante, distinguir de entrada dos valoraciones que sobre la lengua vasca aparecen en los escritos de los primeros colonizadores del Brasil. La primera sería la más previsible: el vasco, como así todavía consta en el Dicionário Aurélio da Língua Portuguesa, es una lengua incomprensible, algarabía de sonidos toscos imposible de escribir. En estos términos se expresó Gabriel Soares de Sousa en su Tratado descriptivo do Brasil em 1587 para explicar como era la lengua de la tribu de los Aymorés, bárbaros entre los más bárbaros: "a sua falla é rouca da voz, a qual arrancam da garganta com muita força, e não se poderá escrever, como vasconço". ${ }^{2}$

${ }^{1}$ Cf. AGUERRE, 1957. p. 456. La importante aportación de elementos vascos en el español de América ha sido aducida convenientemente en otros trabajos. Con todo, conviene resaltar que, en la colonización, el resto de hispanohablantes no dejaban de señalar a los vascos - incluso a gente culta - por su "hablar cerrado" FRAGO, 1999. p. 109.

${ }^{2}$ SOARES, 1938, p.59. Anteriormente, Soares de Sousa para relatar el extremo salvajismo de los Aymorés explica como éstos, aunque eran tupís, "perdieron la lengua", es decir, su idioma ya no tenía contigüidad alguna con el de sus vecinos. La lengua de los Aymorés era, por tanto, incomprensible para cualquier "otro", así como el vasco lo es respecto a los otros idiomas peninsulares:

“... e foram-se para umas serras mui asperas fugindo a um desbarate em que os puzeram seus contrarios, onde residiram muitos annos sem verem outra gente; e os que d'estes descenderam, vieram a perder a linguagem, e fizeram outra nova que se não entende de nenhuma outra nação do gentio de todo este estado do Brasil. E são estes Aymorés tão selvagens que dos outros barbaros, são havidos por mais que barbaros..." SOARES, 1938. p. 58. 
No obstante, nuestro trabajo no se centrará en la acepción de "vasconço" que acabamos de referir, sino en otra concepción de la lengua vasca que seguramente empezaba a circular por los ambientes humanísticos hispánicos de entrado el siglo XVI. El jesuita portugués Manuel de Nóbrega escribía el 10 de agosto de 1549 a su compañero de orden, el navarro Martín Azpilcueta, sobre un compatriota y sobrino de éste, Juan Azpilcueta, "a quién acá llamamos Navarro, por la difficultosa pronunciación que tiene". Nóbrega estaba asombrado por la facilidad que Juan de Azpilcueta ${ }^{3}$ tenía en comunicarse con los nativos del Brasil:

[Juan de Azpilcueta] Anda siempre en las aldeas y hallá duerme y come para les predicar de noche, porque es tiempo en que están juntos y sosegados. Ya sabe la lengua de manera que se entiende con ellos y a todos nos haze ventaja, porque esta lengua parece mucho a la bizcayna. ${ }^{4}$

En una versión portuguesa de esta misma carta se hace todavía más hincapié en esta facilidad innata que poseen los vasco-hablantes para entenderse con los tupís:

... e ja sabe a lingua delles que, ao que parece, muito se conforma com a biscainha, de modo que com elles se entende; e a todos nos leva vantagem, que parece Nosso Senhor ter feito especial graça á nação de Navarra, em acudir aos infieis como fazem Mestre Francisco ${ }^{5}$ nas outras Indias do rei de Portugal e este Padre nas terras

${ }^{3}$ Juan de Azpilcueta, natural de Iriberri, era hijo de Juanes de Azpilcueta y de María de Sebastián. Llevó el sobrenombre de Navarro, como su tío, el doctor Martín Navarro; ITURRIOZ, 1990. p. 227.

${ }^{4}$ LEITE, 1956. p.140-141.

${ }^{5}$ El P. Nóbrega se refiere a Francisco Javier, otro supuesto vasco-hablante y pariente de Martín Azpilcueta. La lengua materna del santo navarro ha sido siempre origen de polémicas, sin todavía poder llegar a ninguna conclusión. Sin duda nació en una localidad en donde durante el siglo XVI se hablaba todavía el vasco. Sin embargo la extracción social de su linaje dificulta la hipótesis que él y su familia utilizaran esta lengua; ver al respecto AGUERRE, 1957 y ALONSO, 2000. p. 60-65. 
do Brasil: onde corre com tanto fervor de uma terra à outra que parece abrazar os montes com o fogo da charidade. ${ }^{6}$

Otro compañero de orden, en este caso el Padre Polanco, secretario de Ignacio de Loyola, también comentó la "facilidad" de Juan de Azpilcueta en comunicarse con los nativos:

En pocos meses aprendió la lengua de ellos, que tenía coincidencias con la cántabra ${ }^{7}$ - que era la natural del Padre Juan -, como se pudo comprobar; de aquí que él los entendiera a los indios, y que los indios le entendieran a él. ${ }^{8}$

Vemos, a tenor de los comentarios de Nóbrega y Polanco, que el vasco era considerado como una lengua, sino similar - y de "difficultosa pronunciación" -, sí más próxima a la de los nativos, el tupí: una lengua puente entre el infiel y el portador del mensaje evangélico, una auténtica Gracia del Señor. Entre las dos concepciones de la lengua vasca - la de Soares como lengua de "bárbaros" y la

\footnotetext{
${ }^{6}$ NÓBREGA, 1988. p. 93
}

${ }^{7}$ Otro elemento a considerar en el problema sobre la primitiva lengua de la Península Ibérica, es la teoría que aunaba en un pasado remoto cántabros y vascos. Así pues, el jesuita Martín de Azpilcueta, el destinatario de la carta de Manuel de Nóbrega comentada anteriormente, se confesó cántabro y navarro a la vez; CARO, 1995. p. 295. Durante también el siglo XVI el vasco-cantabrismo circuló entre algunas figuras intelectuales destacadas, sobre todo del País Vasco, como Martín de Ibarra o el Bachiller Zaldibia. Según parece, esta teoría tuvo su origen en la Edad Media y uno de sus principales propagadores fue Lucas de Tuy (+ 1349) que en su Crónica de España nombra rey de Cantabria al rey de Navarra y cántabros. Su repercusión en Europa está contrastada en uno de los humanistas franceses del siglo XVI, Joseph Justus Scaliger, quien escribió:

"Les Basques sont Cantabres, qui est comme je crois le vieux langage d'Espagne; come il apert par les papiers qui se trouvent dans les villes d'Espagne, Cantabria tenoit la Navarre de delà les Pyrénées, les Basques de deçà \& une partie de la Gascogne" cf. URQUIZU, 1991. p. 26.

${ }^{8}$ Cf. ITURRIOZ 1990. p. 227-228. 
de Nóbrega lengua "pentecostal" - median un poco menos de cuarenta años. Ciertamente, las dos concepciones esconden un horizonte de pensamiento totalmente distinto.

La carta de Nóbrega fue recibida por Martín Azpilcueta en Coimbra, concretamente en el Colégio das Artes, cuya fundación en aquella altura muy reciente - databa del 1542. Es importante resaltar como en esta institución coimbrense, fundada por orden expresa del rey Juan III, tuvieron una especial ascendencia los jesuitas venidos de todos los reinos peninsulares. Podemos citar al jesuita catalán Juan Bosch, ${ }^{9}$ al valenciano Diego Mirón - primer rector de este Colégio -, al canario, pero de origen vasco, José de Anchieta o al ya citado Martín Azpilcueta. No es preciso insistir, por tanto, en la conciencia plurilingue ibérica que se debió experimentar tanto dentro de la propia Compañía de Jesús, con un importante núcleo vasco-hablante, como en la propia ciudad de Coimbra. El vasco no era una lengua remota, bárbara, hablada sólo por gente inculta, sino que era la lengua materna de algunos de los más significativos miembros de la Compañía.

9 "Mestre João Bosch, catalão, mais conhecido por Mossén ou Misser Juan de Aragão "Capellão das Infantas de Castella Dona Maria imperatriz, Dona Joanna mãy del-Rey Dom Sebastião, foi recebido pelo padre Pedro Fabro em Lovayna \& dali mandado ter seu noviciado em Coimbra no anno de 1544 [...] Era amparo de pobres, viuvas e necessitados [...] Morreu em Lisboa na casa de Santo Antão o Velho aos 2 de março de 1533”, Franco, Imagem da Virtude em Noviciado da Companhia de Jesus no Real Collégio de Coimbra em Portugal, vol. II, Évora-Coimbra, 1719; Cf. LEITE I, 1956. p. 114.

El padre Nóbrega, en una carta al P. Simão Rodrigues de Azevedo, fechada en 1549, se refiere a Juan Bosch en estos términos: "Também me parece que mestre João aproveitaria cá muito, porque a sua lingua é similhante a esta [el tupí] e mais aproveitar-nos-hemos cá da sua theologia” NÓBREGA, 1988. p. 75. Ciertamente, la consideración de Nóbrega es sorprendente ya que hemos de suponer que Bosch era hablante exclusivamente románico. Tal vez su plurilingüismo, según Nóbrega, le concedería la fácil adquisición de lenguas. 
El contacto entre los indígenas americanos y marineros vascos también fue frecuente en Terranova, donde llegó a consolidarse una lengua franca. Según refieren varios estudiosos, algunos vocábulos y topónimos de origen vascuence se introdujeron en aquellas lejanas tierras. En la segunda mitad del siglo XVI, el frecuente contacto entre balleneros vascos e indígenas de Terranova incluso dio origen a un "pidgin" vasco-islandés. ${ }^{10}$ Pero es sin duda el comentario de Esteban Garibay, personaje a quien después deberemos dedicarle más atención, que nos pone sobre la misma pista que la apreciación de Nóbrega:

los navegantes de la Provincia de Guipuzcoa y Señorío de Vizcaya, y Tierra de bascos, yendo cada año una vez a Terranova a la pesquería de los bacallaos y ballenas, vienen a deprender esta lengua los salvajes de aquella región, con harta poca comunicación de tiempo breve, que con las gentes una vez al año, en espacio de dos meses. ${ }^{11}$

La lengua vasca es, según comenta Garibay, guipuzcuano de Mondragón, de fácil adquisición, sobretodo para gentes con un nivel rudimentario de cultura; una suerte de lengua elemental, más apta incluso que cualquier otra lengua vulgar predominante, que puede llegar a ser idioma instrumental para el Nuevo Mundo:

Y quando estas gentes silvestres, carecientes de razón, y de todo lo político vienen a deprenderla, quanto con mayor facilidad lo harían las gentes del ordenado vivir de nuestro viejo mundo, siendo necesario, si se diessen a ello. ${ }^{12}$

\footnotetext{
${ }^{10}$ Así es como en el estudio y catálogo de pidgins y criollos de John Holm, aparece referenciado el Pidgin Basque:

"A pidginized forms of Basque was used for trade in the North Atlantic area from about 1550 to 1650 [...] There is lexical evidence of this pidgin in borrowings in indigenous languages spoken around the mouth of the St. Lawrence River and from Labrador to Maine" HOLM, 1988. p. 628.

${ }^{11}$ Cf. ZUBIAUR, 1990. p. 135-136.

${ }^{12}$ Cf. ZUBIAUR, 1990. p. 136.
} 


\section{2- El vasco como protolengua}

El interés por la lengua vasca fue suscitado principalmente a causa de su supuesta antigüedad. A pesar de que el XVI fuera el siglo de la consolidación de las lenguas de estado y de imperio, también lo fue del inicio de los estudios sobre la diversidad lingüística. La lingüística del Renacimiento heredó dos concepciones míticas que debemos abordar: al principio, según la Biblia, hubo una única lengua, el hebreo, otorgada por Dios mismo a Adán; el otro gran mito se encuentra también en el Génesis: el relato del desmoronamiento de la torre Babel servía para justificar el origen de la diversidad lingüística (Gen XI, 1-9). Existían dos pulsiones muy generalizadas entre los humanistas europeos: por una parte, recuperar aquella lengua primigenia, con una evidente nostalgia del paraíso perdido; y por otra, poder llegar a controlar la enorme diversidad lingüística que, con los descubrimientos, se antojaba enorme, imposible de atajar.

En este sentido, durante el siglo XVI hubo un particular impulso en lo referente al estudio del hebreo. Ya no se insistía simplemente en que el hebreo hubiera sido la proto-lengua de la humanidad, sino que se promovió su estudio y su difusión en los círculos humanísticos europeos. Si todas las lenguas derivaban del hebreo, alcanzar a conocer en profundidad esta lengua, significaba aprehender los mecanismos de la diversidad, descubrir los entresijos de la "confusio linguarum".

Pronto los humanistas se darán cuenta que el hebreo no era la vía exclusiva para alcanzar el origen: no se trataba tan sólo de reducir - buscar la lengua primigenia -; en esta búsqueda era indispensable crear una taxonomía, saber clasificar, ordenar, para hacer relucir el sistema latente que une cualquier sistema lingüístico, así como aquello que los separa. Como ha señalado Jean Céard, el resultado de esta búsqueda es un doble movimiento de ida y vuelta: si la búsqueda de la lengua primigenia se orientaba hacia la diversidad de las lenguas, de retorno, la búsqueda de la diversidad 
lingüística era a su vez la búsqueda de la lengua primigenia. ${ }^{13}$ Esta labor de clasificación laboriosa de las lenguas, que con la aparición del "otro" amerindio se aventuraba como fascinante, significaba "descubrir" la variedad ordenada del mundo, la maravilla de la Creación. Así mismo, captar esta "galáxia de línguas", en expresión de Maria Leonor Carvalhão Boescu, era condición previa para recomponer la unidad pre-babélica.

En la clasificación de todas las lenguas conocidas era necesario establecer unos estadios cronológicos: buscar aquellas más remotas, matrices de las demás; en esta labor estaba, por ejemplo Claude Duret, autor del Thresor de l'bistoire des langues de cest univers (1613). Duret defendía el hebreo como lengua primigenia y, por este motivo, la creía lengua universal: cuanto más próximo estaba una lengua de la revelación divina, más cerca estaba de aquella unidad perdida entre la palabra y la cosa. Por tanto, Duret defendía la idea según la cual cuanto más antigua era una lengua más fácil resultaba su aprendizaje, pues en apariencia carecía de complejidad gramatical. Y, a su vez, esa supuesta lengua remota debería ser más universal, por ser más elemental y más próxima a aquella unidad adámica: ${ }^{14}$

les langues sont suceptibles d'être ramenées à un nombre limité de "matrices ou mères de toutes les autres langues, quelque innumerables qu'elles soient", selon l'expression de Duret, [...] En somme, la variété n'est pas prolifération sans ordre [...] La confussion des langues, qui est certes un châtiment, est aussi un aspect de la variété ordonné du monde. ${ }^{15}$

${ }^{13}$ CÉARD, 1980. p. 577.

${ }^{14}$ Maria Leonor Carvalhão Buescu, comentando los postulados gramaticales del humanismo portugués, hace las siguientes consideraciones:

"Nomes naturais, correspondendo a coisas naturais, numa profunda e perfeita harmonia primordial? Sugestão que, apontando para uma arquilíngua, "língua elementar", repousa sobre a absoluta sabedoria da natureza pura sempre recém-criada? Sugestão que, derivando da colocação de um problema a nível filosófico, não deixa de ser também uma sugestão poética, de que o simbolismo moderno irá fazer coisa sua" BUESCU, 1984. p.192. ${ }^{15}$ CÉARD, 1980. p. 581. 
En este sentido, cabría revisar la imagen del mito de Babel en el siglo XVI. El desmoronamiento de la torre no sería tan solo un castigo, sino el resorte necesario, instituido por Dios mismo, para configurar la variedad de naciones y de lenguas del mundo, expresión de su omnipotencia creadora. ${ }^{16}$ El humanista francés Joseph Justus Scaliger al describir la extensión de la lengua vasca, hace la siguiente comparación:

C'est un langage estrange que le Basque, c'est le vieil Espagnol, come le Breton bretonnant est le vieux Anglois. On dit, qu'ils s'entendent, ie n'en croy rien, ils nomment pain \& vin de mesme, mais le reste est bien different. J'ay leur Bible. ${ }^{17}$

Según Scaliger, el bretón es para el francés lo que el vasco es para el español, pero también el humanista francés introduce otra idea que, si bien desacredita, no deja de relucir: el bretón y el vasco tienen puntos de contacto porque coinciden en su origen remoto, en un período o estadio ignoto. Scaliger, por tanto, apunta hacia la

${ }^{16}$ Así lo ha expresado recientemente Félix de Azúa en un análisis del mito de Babel en el Romanticismo alemán:

"Si adoptamos un juicio positivo, la dispersión, ateniéndonos a la traducción literal, no es el castigo de ningún desafío, ni se produce "con dolor"; es tan sólo una práctica técnica de la Providencia para que los mortales pueblen la tierra, ya que ése es el proyecto divino y condición para la existencia misma de los humanos" AZÚA, 1996. p. 25.

Sin duda, la exégesis rabínica impuso la interpretación en que se culpabilizaba a los hombres y de esta manera se justificaba la existencia de un solo pueblo elegido. Esta interpretación rabínica pasó sin ningún obstáculo al cristianismo y al humanismo renacentista. Así, autores como Flavio Josefo en sus Antigüedades Judaicas, Filón de Alejandría en De confusione linguarum o el Pseudo Filón en sus Antigüedades Bíblicas serán recogidos - por poner un ejemplo bien significativo - por Dante en su De Vulgari Eloquentia. En el caso español, Juan de Mariana en su Historia General de España hace una interpretación del desmoronamiento de la Torre de Babel deudora - como muy bien señaló María Rosa LIDA, 1970. p. 24-25 - de la rabínica de Flavio Josefo.

${ }^{17}$ Cf. URQUIZU, 1991. p. 26. 
caracterización del vasco y del bretón como lenguas matrices del español y del francés respectivamente.

Los planteamientos universalistas de la lingüística del siglo XVI tuvieron también su expresión en las gramáticas que los misioneros, desde cualquier remoto lugar del planeta, redactaban. La necesidad de reducir unos nuevos sonidos al alfabeto latino o ajustar una lengua amerindia a una "ars", como si de una lengua clásica se tratara, fue un ejercicio en que se ponían a prueba aquel universalismo que se defendía en la teoría. Ciertamente, plantea-mientos que no dejan de acercarnos a los universales lingüísticos que con tanto tesón han defendido en este siglo Chomsky y sus seguidores:

As últimas décadas assitiram ao retorno da denominação gramática universal à literatura lingüística, como reflexo da obra de Noam Chomsky (1928- ) e de seus seguidores. A hipótese de um núcleo comum para todas as línguas radica, no entanto, numa tradição que remonta à Idade Média. Os pressupostos que levaram estudiosos do passado à concepção da existência de semelhanças entre as línguas são de natureza diversa dos fundamentos biológicos levados em conta atualmente: no Occidente cristão considerava-se que o dom recebido diretamente de Deus por Adão fora encoberto pela confusão de línguas criada por Deus como punição aos homens. É como reflexo deste segundo contexto que examinamos gramáticas missionárias escritas no Brasil de Quinhentos e de Seiscentos, exemplificadas pelos trabalhos dos jesuítas Anchieta (1595), Figueira (1621?), Dias (1697) e Mamiani (1699). Embora voltadas para o aprendizado de línguas estrangeiras não-indoeuropéias, essas obras demonstram, apesar das diferenças marcantes em relação ao latim e às línguas nativas de seus autores, a crença em características comuns a todas as línguas. ${ }^{18}$

${ }^{18}$ ROSA, 1996. p. 1. 


\section{3- Situación y valoración del vasco durante el siglo XVI}

El vasco a principios del siglo XVI disfrutaba de una extensión mucho mayor que la actual. Sin embargo, era una lengua sin ningún tipo de ascendiente cultural: no disponía de una literatura culta y se había mantenido ajena a cualquier movimiento tendente a prestigiar su uso durante la Edad Media; no es hasta el 1545 en Burdeos que se imprime el primer libro en vasco.

No obstante, bien entrada la segunda mitad del siglo XVI, la mención al vasco se convierte en una referencia obligada por ser considerada la lengua más antigua de España. Ello se debe fundamentalmente gracias a una explicación de origen bíblico. Cuando los hijos y nietos de Noé se dispersaron por la tierra después del Diluvio poblaron la tierra: "Hae sunt generationes filiorum Noe; Sem, Cham et Japheth: natique sunt eis filii post diluvium. Filii Japheth: Gomer et Magog et Madai et Javam et Thubal et Mosoch et Thiras" (Génesis X, 1-2). El historiador judío romanizado, Flavio Josefo, en sus Antigüedades judaicas (I, 6, 124) glosó el pasaje bíblico, introduciendo los pueblos donde se dispersó la descendencia de Noé. A Túbal le correspondió ser el fundador de los íberos. Este dato fue recogido por San Jerónimo (In Isaiam XVIII, 66) e incorporado a la patrística cristiana. De esta leyenda ya se hizo eco Isidoro de Sevilla en sus Etimologías "Thubal, a quo Iberi, qui et Hispani" (IX, 2, 29); ${ }^{19}$ y pasó sin mayor problema a todas las principales crónicas y cronicones medievales peninsulares. ${ }^{20} \mathrm{La}$ Península Ibérica tendría el honor de haber acogido no sólo uno de los linajes más remotos de la tierra, sino también de haber conservado restos de aquel pasado bíblico post diluvium y anterior a la torre de Babel. Entre estos restos figuraba la remota lengua del linaje que algunas personalidades del siglo XVI identificaron con el vasco.

\footnotetext{
${ }^{19}$ Cf. LIDA, 1970. p. 16.

${ }^{20}$ LIDA, 1970 y TOVAR, 1980.
} 
Cuando se planteó el problema la lengua originaria de Hispania, ya diversos humanistas del siglo XVI dieron su opinión apuntando al carácter arcaico del vascuence. Lucio Marineo Sículo (1460-1563) cronista de los reyes católicos, en el libro IV de su De rebus memorabilus (1530) trata de

quál fue antiguamente la lengua española" y continua "que los primeros moradores de España, según que algunos dizen, todos usaron la lengua Vizcaína hasta la venida de los Romanos y Cartagineses. ${ }^{21}$

Podemos observar, como Sículo toma la prevención de "según que algunos dizen", para exponer la supuesta antigüedad y extensión de la lengua vasca. El valenciano Pero Anton Beuter negará esta supuesta antigüedad y extensión por la disconformidad obvia de la lengua vasca con las del resto que se hablan en la península, pero también por el alejamiento de la lengua vasca respecto el arameo y el caldeo, a priori, las lenguas más antiguas del planeta. ${ }^{22}$ Si bien la teoría del vasco primitivo se sustentaba en una larga tradición fundamentada en textos medievales, no hubo unanimidad ante ella. Y más, cuanto tuvo que rivalizar con la creciente apología de la lengua española que en aquella altura se convertía en lengua de imperio.

El hombre que vinculó de manera clara y rotunda la antigüedad del vasco con la descendencia de Túbal fue el ya citado Esteban de Garibay, artífice de la teoría vasco-iberista que tanta fortuna ha tenido en la erudición española. ${ }^{23}$ Más recientemente, Jon Juaristi también ha señalado al cronista de Felipe II como el precursor de esta teoría:

El primero en unir a Túbal con la lengua vasca fue el guipuzcuano Esteban de Garibay y Zamalloa (1533-1599), cronista de Felipe II. Garibay fue, en consecuencia, el artífice del Túbalismo y el

\footnotetext{
${ }^{21}$ Cf. URQUIZU, 1991. p. 24.

22 ZUBIAUR, 1990. p. 71.

${ }^{23}$ Ver al respecto el imprescindible estudio de Julio Caro Baroja, particularmente: Origenes del vasco-iberismo, CARO, 1995. p. 294-295.
} 
precursor de la teoría vasco-ibérica defendida siglos después por Wilhelm von Humboldt y Ramón Menéndez Pidal, entre otros. ${ }^{24}$

\section{4- EI vasco en las letras portuguesas}

Los vascos aparecen en la literatura portuguesa muchas veces como reflejo de la imagen que la literatura española había ya creado: gentes poseedoras de una algarabía incomprensible y unos pésimos hablantes de romance que subvertían, de manera cómica, el orden de las letras. Así João de Barros en su Gramática de 1539, en el capítulo referente a las figuras, trata la metástasis, dando como ejemplos "trocar" por "torcar" o "apretar" por "apertar" y añade "como os que falam vasconço que trocam huas letras por outras." 25

Más allá de estas referencias tópicas, hallamos en los escritos de carácter reivindicativo de la lengua portuguesa alguna que otra mención interesante al "vasconço". Al igual que sucede con los colonizadores del Brasil, existe cierta contradicción en el reconocimiento de una lengua tan abstrusa - y hasta cómica -, como fascinante en su misterio.

También es João de Barros, esta vez en su Diálogo em louvor da nossa linguagem quien desacredita el vasco, rebajándolo a una categoría de habla, imposible de llevarlo a la escrita, al mismo nivel del seseo gitano de Sevilla: "(Pay)- Çerto é que a língua castelhana muito melhor é que o vasconço de Biscaya e o çeçear çigano de Sevilha, as quaes nam se podem escrever." 26 En la misma obra, João de Barros utiliza "vasconço" con otra acepción; no tanto como un habla, sino como un hápax tan hermético como inútil:

(Pay) E se lhe faleçera algum termo soçinto, fizera ô que vemos em muitas partes aos presentes; os quaes quando careçem de termos theologaes, os theólogos pera intendimento real da cousa ôs compuseram, e assy os filósofos, mathemáticos, juristas, médicos:

\footnotetext{
${ }^{24}$ JUARISTI, 1992. p. 22.

${ }^{25}$ Cf. MICHÄELIS, 1924. p. 189.

${ }^{26}$ BARROS, 1959. p. 76-77.
} 
todos antre sy trazem termos que nam sam latinos nem gregos, mas casy hum vasconço de artes, em que os homees gastam tantos annos. ${ }^{27}$

Si bien en el Portugal del siglo XVI era más o menos admitida la vinculación de la lengua portuguesa al latín, ello no impedía la referencia obligada a la lengua "originaria" de la Península Ibérica; sobretodo, porque ya desde la Edad Media, en Castilla, se sacaba a colación el topónimo Setúbal para justificar el origen bíblico de los primeros pobladores peninsulares:

Ya viniera el nombre Cetúbales (y, por consiguiente, de la ciudad de Setúbal) de cetus Tubalis, como propone el Arzobispo don Rodrigo, y, como más tarde se dijo, se Sem y Túbal (Covarrubias, s.v. Setúbal) o de Sedes Tubalis (M. del Barco Centenera), lo cierto es que la ciudad quedó muy aferrada en el saber vulgar a su supuesto epónimo (Lida, 1970: 18-19). ${ }^{28}$

En el contexto europeo renacentista, el tubalismo no representa ninguna novedad en sus planteamientos. Fue en este periodo cuando nacieron gran parte de los mitos sobre el nacimiento de los grandes pueblos y naciones, los llamados mitos "noénidas". Guillaume Postel, 1510-1581, titular desde 1539 de la cátedra de hebreo del Collège de France, defendía que Noé, también llamado Jano por los latinos, fue el antepasado común de etrurios, galos y cimbrios.

\footnotetext{
${ }^{27}$ BARROS, 1956. p. 80.
}

${ }^{28}$ LIDA, 1970. p. 18-19. Ya en el siglo XVI, el jesuita Juan de Mariana, otro defensor de las tesis tubalistas, citaba la población portuguesa de Setúbal como un lugar probable en donde la descendencia de Noé desembarcara en la Península, sólo en competencia con la hipótesis de Tafalla o Tudela navarras:

"De los reyes fabulosos de España. Averiguada cosa y cierta es, conforme a lo que de suso queda dicho, que Túbal vina a España; mas en qué lugares hiciese su asiento, y qué parte de España primeramente comenzase a poblar y cultivalla, no lo podemos averiguar, ni hay para qué adivinallo; dado que algunos piensan que en la Lusitania; otros que en aquella parte de los vascones que se llama hoy Navarra. Toman para decir este argumento los portugueses de Setúbal, pueblo de Portugal; los Navarros de Tafalla y Tudela..." Cf. LIDA, 1970. p. 26. 
João de Barros nunca se refirió a la supuesta llegada de la descendencia de Noé a la Península, lo que no deja de ser significativo, pues debía ser un episodio suficientemente conocido entre los humanistas portugueses. En cambio, sí que la leyenda aparece en la gramática Fernão de Oliveira (1536), quien comenta: "Noé edificou em esta terra Noela e Noegla cidades..." 29

Duarte Nunes de Leão en su Origem da lingua portuguesa, si bien defendió la llegada de Túbal a la Península, no admitió la etimología: Túbal > Setúbal. Según el autor portugués el origen del topónimo lusitano es Cetóbriga, ciudad de pescadores. En cambio, Nunes de Leão se mostró favorable a que Túbal quizás se hubiera aposentado en Vizcaya, cuya lengua es un pálido reflejo del antiguo caldaico:

Outros espanhóis, não contentes de vir Túbal a este reino de Portugal, o fazem dar consigo nas montanhas de Biscaia [...] Desta vinda de Túbal a Espanha vêm a cologir que a primeira língua que nela se falou foi a caldaica e que dela procedeu o vasconço que em Biscaia se falava, e que aí se conservou como em lugar menos frequentado. ${ }^{30}$

Nunes de Leão defendía el "vasconço" como una suerte de caldeo transformado por el curso de los años. A su vez debemos entender, según afirma el mismo autor, que el caldeo fue el registro hablado del hebreo. De esta manera, llegaríamos a una misma intención que hemos visto repetidas veces entre los autores del siglo XVI: el "vasconço", como también lo fue su antepasado, el caldeo, es una lengua exclusivamente hablada, jamás escrita. ${ }^{31}$

${ }^{29}$ Cf. BUESCU, 1984. p. 159.

${ }^{30}$ Cf. BUESCU, 1984. p. 206.

${ }^{31}$ Otro extranjero, en este caso el veneciano Andrea Navagero, escribía en su paso por el País Vasco, entre los años 1524-1526, sobre la lengua vasca:

"es una lengua particular, que no tiene ninguna palabra castellana ni de ningún otro idioma, de modo que fácilmente se puede creer que ésta era la antigua lengua de los españoles antes de la venida de los romanos; no tiene escritura propia; por tanto, para escribirla aprenden castellano y escriben con sus letras; así que los más de los hombres lo saben, pero las mujeres no conocen más que su habla nativa" Cf. URQUIZU, 1991. p. 24.

El vasco, pues, no se escribía y se reducía al ámbito del habla. 
Llegados a este punto deberíamos reflexionar sobre la dimensión que adquiere el problema sobre la lengua original de Hispania, problema donde emergen cuestiones no solamente lingüísticas, sino - y sobre todo - políticas, religiosas y filosóficas:

o problema da língua original de Espanha, remetida para a incerteza histórica ou remontando a uma antiguidade "provável", liga-se a uma área especulativa do conhecimento, transcendendo a historiografia e até a cronística e prende-se às questões epistemológicas da origem e natureza da linguagem. Deixa, pois, de ser encarado e abordado como um problema resolúvel em termos de história "profana" e entra no circuito do pensamento em torno do sagrado. ${ }^{32}$

Es aquí donde queremos hacer un especial hincapié, ya que la referencia, aunque sea mínima, de la lengua vasca pasa de la simple curiosidad científica y erudita a una explicación mítica, cercana a la Revelación.

\section{5- Universalismo y la Compañía de Jesús}

El universalismo fue una característica y una vocación de la Compañía de Jesús desde sus inicios. Aunque la especulación lingüística no fue nunca un fin en sí mismo, está claro que tenía que ser un paso previo para la divulgación pastoral en el mundo. Uno de los nombres que ha salido anteriormente a colación: Guillaume Postel - visionario, cabalista y reputado lingüista -, fue miembro durante un año de la Compañía. Umberto Eco dedica un comentario a la relación de éste con Ignacio de Loyola:

Postel intenta en primer lugar convencer de sus ideas a Francisco I, el cual lo considera un exaltado; después, una vez perdido el favor en la corte, se dirige a Roma con la intención de convencer de su utopía a Ignacio de Loyola, cuyo ideal de reforma le parece afín al suyo (y durante mucho tiempo considerará a los jesuitas

32 BUESCU, 1984. p. 203. 
como el instrumento divino para la realización de la concordia en el mundo). Naturalmente, Ignacio advierte que los objetivos de Postel son distintos a los de los jesuitas (la propuesta de Postel cuestiona el voto de obediencia al papa y, además, Ignacio era español y la idea de que el rey de Francia fuese el rey del mundo no le debía hacer mucha gracia). Al cabo de un año y medio Postel fue obligado a dejar la Compañía. ${ }^{33}$

Guillaume Postel promovía la "restitución" del hebreo como lengua de la concordia universal. El hecho que el visionario creyese a la Compañía de Jesús como el instrumento más válido para conseguir esa concordia en el mundo, capaz de aunar toda las sinergias universalistas de la época, no parece tan extraño. Sin embargo, también es evidente que Ignacio de Loyola, de una ortodoxia intachable, no podía ver con buenos ojos a un estrafalario personaje que mezclaba alegremente cábala, profetismo o política sin ningún tipo de escrúpulo dogmático.

El reconocimiento del vasco como lengua antigua, debió circular entre los padres jesuitas, no sólo entre los residentes en la Península Ibérica, sino también allende de sus fronteras. Este sería el caso de Diogo de Gouveia, principal del colegio de Sainte Barbare de París y uno de los más destacados nombres del humanismo portugués del siglo XVI. Diogo de Guveia traduce al francés una carta del 21 de enero de 1545 de Francisco Javier a Ignacio de Loyola y al resto de los compañeros de orden residentes en Europa: "donque veu que ne les entendoys ne eulx moy, car leur langue estoit Malauar \& la mienne Celtiberique vulgairement appellee vasquenza qui est au pays dhespaigne". ${ }^{34}$

El original de la carta también tuvo su traducción - y supervisión - al latín por encargo del propio Ignacio de Loyola en Roma:

33 ECO, 1994. p. 74.

34 "Copie d'une lettre missive envoiee des Indes, par monsieur maistre François Xavier frere tres chier en Ihesucrist, de la societe du nom de Ihesusm a son preuost monsieur Egnace de Loyola, \& a tous ses freres estudians aux lettres a Romme, Pavie, Portugal, Valence, Coulogne, \& a Paris" Cf. AGUERRE, 1957. p. 457. 
"Cum ergo neque illi me neque ego illos intelligerem, lingua quippe eorum erat malauar, mea vero celtiberica, vulgo vazquenza."

Ciertamente, es difícil de creer que un navarro tenga la necesidad de añadir a un vasco la explicación respecto a su lengua materna supuestamente común: "la mienne Celtiberique vulgairement appelee vasquenza”. Parece que el autor de esta aclaración es el traductor, Diogo de Gouveia, quien para dignificar la lengua de uno de los compañeros más destacados de su orden, la tilda de "celtibérica". ${ }^{35}$ Diogo de Gouveia debía estar al corriente de las teorías que sobre la supuesta antigüedad de la lengua vasca circulaban por España. Celtibérico ${ }^{36}$ era un adjetivo lo suficientemente remoto para un hombre del siglo XVI, que lo podía retrotraer a un periodo incierto: el de los fundadores de un territorio. Esteban de Garibay, firme en sus convicciones vasco-iberistas, había manifestado: "iberos que son los españoles, de los quales iberos fueron llamados los celtíberos." ${ }^{37}$ Garibay no dudaba en que la lengua de estos celtíberos fuera, sin lugar a dudas, el vasco; como tampoco parecía dudarlo Diogo de Gouveia.

35 Según José Aguerre:

"Una curiosidad notable presentan ambos textos. Aquí el gentilicio que se emplea para la lengua de Francisco no es bizcaina sino celtibérica, vulgo vazquenza; lo cual tiene el aire de una corrección de "ajuste". Se trata de una corrección que pudiéramos llamar "inteligente", como podían hacerla ciertamente Ignacio de Loyola y Mr. Gouvea" AGUERRE, 1957. p. 461-462.

${ }^{36}$ Existía incluso la teoría que la Península Ibérica recibió en su antigüedad la denominación de Cetubalia, por ser habitada en su inicio por la descendencia de Túbal. Antonio de Nebrija cargó contra esta teoría carente de cualquier tradición:

"I aun no pára en esto la locura de aquéllos, mas aun añaden que de Cetubalia, corrompido el nombre, se llamó después Celtiberia. ¡Ombres perdidos $\mathrm{i}$ agenos de todas letras $\mathrm{i}$ artes de humanidad que quieren presuponer por verdadero lo que nunca fue! Cf. LIDA, 1970. p. 21.

${ }^{37}$ Cf. CARO, 1995. p. 294. 


\section{6- Conclusiones}

Las primeras impresiones de Brasil como una especie de Paraíso Perdido - sobre todo construidas a partir de la Carta do Achamento de Pêro Vaz de Caminha - propiciaron la idea de que las lenguas amerindias, lenguas de aquel Edén re-encontrado, estaban más cerca de la lengua adámica. Como ha comentado Vecchi, se produjo una extraña aproximación a un mundo utópico:

La approssimazione forse solo letteraria degli indigeni al modello culturale dei portoghesi si accorda un movimento sincronico di progressivo, solo in parte consapevole, riconoscimento dei valori specifici di quell'alterità umana come il riflesso tenue confinato anch'esso nella memoria di un tempo propio ed anteriore. La rappresentazione dell'umanità indigena contrassegnata sino all'eccesso dagli attributi propi del mondo infantile offre un'ulteriore ratifica della presenza di una vena utopica nella Carta. ${ }^{38}$

El viaje a las Indias no era sólo un viaje a través de un territorio, sino también a través del tiempo: un tiempo fundacional. La inquietante alteridad se sublimaba con la insistencia de una representación adámica de aquel tiempo "propio ed anteriore". Como observó Covarrubias en su Diccionario (s.v. España): "Antiguamente España devió ser para las otras naciones lo que agora las Indias para nosotros, como consta de muchos autores..."39 El descubrimiento provoca la reacción de compulsar las noticias que llegan del Nuevo Mundo con los compendios más autorizados y la necesidad de filiar los remotos topónimos con las novedades llegadas de América.

Una reflexión muy similar hizo el licenciado Poza, autor de la Antigua lengua de las Españas (1587) y exponente de las teorías tubalistas, quien comparó la situación de los primeros pobladores de la península, con el descubrimiento de las Indias:

${ }^{38}$ VECCHI, 1994. p. 12.

${ }^{39}$ Cf. LIDA, 1970. p. 14. 
así como ahora nuestros españoles en las Indias, sin embargo, de su lengua castellana, todavía nombran las provincias con sus nombres primeros de la lengua indiana: México, Perú, Chile, Cuzco, etcétera. De suerte que ya por este ejemplo se entenderá la causa, porque los nombres de los Reyes, ríos, ciudades y poblaciones que fueron fundadas en aquellos primeros siglos más allegados al diluvio, todos ellos son de la dicha lengua primera general que se hablaba por el mundo antes de la confusión de Babilonia. ${ }^{40}$

Un proceder al que tampoco Esteban de Garibay estuvo al margen. Sus paralelismos vasco-armenios en comparar, por ejemplo, "Gorbea" con "Gordeya" o el "Araxes" guipuzcuano con el "Araxes" virgiliano de Armenia, sirven para justificar un razonamiento sobre la labor de colonización en el Nuevo Mundo. Así lo explica Caro Baroja:

hay algo que da la razón funcional de esta tendencia a lo que los etnólogos alemanes llamarían "Ferninterpretation". Si los españoles en Indias han llamado Toledo, Trujillo o Granada a las ciudades que fundaban: ¿Por qué los íberos, mejor dicho, sus reyes, no iban a dejar memoria similar de sus asentamientos viniendo de la lejana Asia a estas latitudes? ${ }^{41}$

Vemos, pues, que el tubalismo se argumentaba también con la praxis colonizadora de las Indias: un proceso que llevaba a reflexionar a los humanistas sobre el periodo de la fundación de su propio país. Será con el conocimiento y contacto más profundo, que la ucronía adámica empezará a disolverse. Pronto los colonizadores se darán cuenta lo dificultoso que era comunicarse con el indígena: los indios, para su desgracia, no hablaban ninguna lengua remota. Para unos era una lengua infernal, imposible de aprender. La lengua de los aimorés o de los tapuias era un auténtico caos: "Chamão-se Aymorés, a lingoa delles he differente dos outros indios, ningem os entende." 42

\footnotetext{
${ }^{40}$ POZA, 1959. fol. 9v.

${ }^{41}$ CARO, 1995. p. 294.

${ }^{42}$ GÂNDAVO, [s.d.]. p. 32.
} 
Así, como afirma Pêro de Malgalhães Gândavo, sin poder entenderlos, difícilmente podrían ser los habitantes del Paraíso. La incomprensión lingüística ayudó en buena medida a la demonización del indio que se produjo ya a partir de la segunda generación de colonos. Recordemos la famosa frase de Gândavo, el cual, a partir de un dato lingüístico, realiza toda una valorización moral del indígena:

A língua deste gentio toda pela Costa he uma: carece de tres letras -scilicet, não se acha nella F, nem L, nem R, cousa digna de espanto, porque assi não têm Fé, nem Lei, nem Rei; e desta maneira vivem sem Justiça e desordenadamente. ${ }^{43}$

Sin embargo, también hubo colonizadores más perseverantes que intentaron aproximarse a la lengua de los nativos. José de Anchieta trató de "reduzir" en una sola lengua "geral" todos los sistemas lingüísticos de la costa del Brasil. ${ }^{44}$ Para Anchieta y sus colaboradores, los tupís hablaban una lengua capaz de convertirse en instrumento pastoral y de doctrina. Así, los misioneros que llegaban al Brasil debían pasar por el estudio del método de Anchieta; en una carta del padre João de Melo al padre Gonçalo Vaz de Melo, fechada en Bahía el 13 de septiembre de 1560, se expresaba en los siguientes términos:

Logo que o Padre [Luís de Grãa] aquy chegou, ordenou que em casa se lesse a arte da lingoa brasilica, que compôs o Irmão Joseph [Anchieta], e o mestre Padre hé o mestre e estáa tam exercitado e

${ }^{43}$ GÂNDAVO, [s.d.]. p. 49.

${ }^{44}$ Autor de Arte de gramatica da lingoa mais usada na costa do Brasil feyta pelo padre Ioseph de Anchieta da Companhia de IESU. Coimbra por António de Mariz, 1595. El texto manuscrito ya era utilizado en Bahía el 1556, en 1560 Luis de Grã sancionaba el método como obligatorio para los miembros de la compañía destinados a Brasil y en 1592 se solicita licencia para ser impreso. En el ya citado estudio y catálogo de pidgins y criollos, John Holme hace referencia también a la "língua geral", si bien explicitando que no se trata tanto de un pidgin como de una koiné; HOLM, 1988. p. 605-606. 
instruido nella que leva avantajem nas cousas da arte aos mesmos lingoas. 45

El método Anchieta permitía incluso aventajar a los "lingoas" (intérpretes) en la comunicación con los indígenas.

Aunque también surgió el desaliento entre aquéllos que estudiaban el método de Anchieta y no conseguían comunicarse con los indígenas. En 1569 el padre António Pires se exclamaba:

mas creo que o faz para nos envergonhar e para nos fazer enveja, coma na verdade a mym me envergonha, que há XII annos que quá ando e não sey nada. Agora começo polos nominativos por a arte para poder aprender. ${ }^{46}$

¿Cuánto tiempo perdió el iluso padre Pires estudiando unos nominativos inexistentes? Sólo la primera generación de misioneros de Brasil pudo soñar con un milagro pentecostal, milagro que en boca de Nóbrega tomó la sorprendente imagen del vasco.

Reacciones y perspectivas sin duda bien díspares, reflejo del drama de la alteridad, tan inaudita como fascinante. De esta manera, un tema mínimo que podría pasar desapercibido o como un simple error de Manuel de Nóbrega, se relaciona con aspectos básicos de las teorías lingüísticas del siglo XVI - lengua matriz, posibilidad de creación de una lengua universal, reducción de todas las lenguas a una sola "ars" según el modelo greco-latino, etc. - teorías todas ellas que se funden en el crisol de la Compañía de Jesús, tan necesitada de reflexiones lingüísticas como de instrumentos para llevar un nuevo pentacostés a la Babel pagana. Algunos de ellos fueron "iluminados", incómodos en su propia orden, como Guillaume Postel o Athanasius Kircher. Otros, brillantes lingüistas, como José de Anchieta abrieron paso al cristianismo con su extraordinario don en el Nuevo Mundo. En todos ellos, incluso en aquéllos que aparentemente estaban apartados de las polémicas científicas sobre la lengua, encontramos un eco de aquella preocupación.

\footnotetext{
${ }^{45}$ LEITE, 1958. p. 283.

${ }^{46}$ LEITE, 1958. p. 311.
} 


\section{Referências Bibliográficas}

AGUERRE, José. El habla materna de San Francisco Xavier. Príncipe de Viana, p. 451-462, 1957. [En buena medida, versión española del artículo del P. Georg Schurhammer aparecido en la Revista Internacional de Estudios Vascos (1929)].

ALONSO, Eduardo Javier. Los escritos portugueses de San Francisco Javier. Braga: Universidade do Minho, 2000.

ARTECHE, José de. Aproximaciones vasco portuguesas. Museu de etnografia e história. Porto: Junta directiva de Porto, 1967.

AZÚA, Félix de. Siempre en Babel. Archipiélago, Barcelona, núm. 26-27, p. 22-32, 1996.

BARROS, João de. Diálogo em Louvor da Nossa Linguagem a cura di Luciana Stegagno Picchio. Roma: Instituto di Filologia Romanza dell'Università di Roma, 1959.

BUESCU, Maria Leonor Carvalhão, Historiografia da lingua portuguesa, século XVI. Lisboa: Livraria Sá de Costa, 1984.

CARO, Julio, Los vascos y la historia a través de Garibay en Nosotros los Vascos t. III. p. 213-382. Bilbao: Lur, 1995.

CÉARD, Jean, De Babel à la Pentecôte: la transformation du mythe de la confusion des langues au XVIe siècle, Bibliothèque d'Humanisme et Renaissance, Paris, vol. XLII, p. 577-594, 1980.

ECO, Umberto. La búsqueda de la lengua perfecta en la cultura europea. Barcelona: Crítica, 1994.

FRAGO, Juan Antonio, Vascos en Indias, p. 101-134. En: Historia del español de América. Madrid: Gredos, 1999.

GANDAVO, Pêro de Magalhães. Tratado da Terra do Brasil. Rio de Janeiro: Anuário do Brasil, [s.d.].

HOLM, John. Pidgins and Creoles, Volume II. Reference Survey. Cambridge: Cambridge University Press, 1988.

ITURRIOZ , Jesús. Primeras "Misiones" de Jesuitas al Brasil (1549-1553). En: Los Vascos y América. Ideas, Hechos, Hombres. Coordinador: Ignacio Arana Pérez. Madrid: Espasa-Calpe/Argantonio, 1990.

JUARISTI, Jon. Vestigios de Babel. Para una arqueología de los nacionalismos españoles. Madrid. Siglo Veintiuno, 1992. 
LEÃO, Duarte Nunes de. Origem da Lingua Portuguesa. Edição e estudo de José Pedro Machado. Lisboa: Cultura Literária, 1945.

LEITE, Serafim. Monumenta Brasiliae I (1538-1553) por Serafim Leite s.i. In Monumenta Missionum Societatis Iesu vol. X Missiones Occidentales. Roma: Monumenta Historica, 1956.

LEITE, Serafim. Monumenta Brasiliae III (1558-1563) por Serafim Leite s.i. In Monumenta Missionum Societatis Iesu vol. XII Missiones Occidentales. Roma: Monumenta Historica, 1958.

LIDA, María Rosa. Túbal, primer poblador de España, Abaco, nº3, p. 11-48, 1970.

MICHAELIS, Carolina. Elementos bascos em Portugal, Revue internationale des études basques, vol. XV, p. 188-190, 1924.

NÓBREGA, Manoel de. Cartas do Brasil. Itatiaia-Belo Horizonte: Ed. da Universidade de São Paulo, 1988 [Reimpresión de la edición de 1931].

POZA, Andrés de. De la antigua Lengua de las Españas. Bilbao: Matías Mares, 1959.

ROSA, Maria Carlota. As línguas bárbaras e peregrinas do Novo Mundo segundo os gramáticos jesuítas. Tese de mestrado inédita. Rio de Janeiro: Universidade Federal, 1996.

TOVAR, Antonio. Mitología e ideología sobre la lengua vasca. Madrid: Alianza Editorial, 1980.

VECCHI, Roberto. Il paradigma ibrido dell'utopia portoghese del Cinquecento, Rassegna Iberistica, vol. 49, p. 3-21, 1994.

ZUBIAUR, José Ramón. Las ideas lingüísticas vascas en el siglo XVI. San Sebastián: Universidad de Deusto, 1990.

\section{Resumen}

El vasco, por su caracterización como protolengua o lengua matriz y por el hecho de ser la lengua materna de prestigiosos jesuitas, participó en las especulaciones lingüísticas que intentaban ver la colonización de América como la descubierta de un tiempo remoto y prebabélico.

\section{Abstract}

The fact that the basc was considered as a protolanguage as well as being the mother tongue of some of the most prestigious Jesuits was the main reason for the speculation about the colonization of America as a discovery of an ancient pre-Babel time. 